\title{
Effect of Design Parameter of Hydraulic Shock Absorber of Heavy Truck Air Suspension System on Road Surface Friendliness
}

\author{
Bui Van Cuong, Vi Thi Phuong Thao, Doan Thanh Binh, Nguyen Thanh Cong
}

\begin{abstract}
This paper presents an effect analysis of design parameter of hydraulic shock absorber of heavy truck air suspension system on road surface friendliness. In order to analyze the effect of design parameters of a hydraulic shock absorber in combination with an air elastic element of an air suspension system, a dynamic model of both hydraulic shock absorber and air spring is established to determine vertical force. And then this vertical force of an air spring is connected to a quarter-vehicle dynamic model of a heavy truck to analyze the effect of the damping coefficients of hydraulic shock absorber on road surface friendliness. A dynamic load coefficient (DLC) is chosen to analyze road surface friendliness. The design parameters of shock absorber respectively are analyzed and evaluated its effect on road surface friendliness. The results indicate that the value of hydraulic shock absorber damping coefficient has a significant effect on the ability to reduce vibrations to the road surface.
\end{abstract}

Index Terms-Heavy truck, Hydraulic shock absorber, Suspension, Air Spring, Friendliness.

\section{INTRODUCTION}

Vehicle dynamic load acting on the road surface is one of the causes of road surface destruction. The suspension system plays an important role in improving the ride comfort of the vehicle as well as reducing the dynamic loads of the wheels acting on the road surface. Viscous damping is an important suspension parameter which must be optimized to make a full contribution to the improvement of vehicle vertical response. The viscous damping characteristics of hydraulic shock absorber were proposed and evaluated its effect on road friendliness [1]. Air suspension systems of a truck was proved to be effective on vehicle ride comfort and road surface friendliness under the operating condition based on a quarter vehicle dynamic model [2]. The optimal parameters of the air suspension system of a semi-trailer truck were found via the genetic algorithm (GA) based on a half-vehicle dynamic model in the direction of the design "road-friendly" vehicles $[3,4]$. The optimal parameters of the walking-beam suspension system of a heavy truck were found via the genetic algorithm (GA) [5]. The dynamic models of the traditional and new air suspension systems were proposed to

Bui Van Cuong, Faculty of Automotive and Power Machinery Engineering, Thai Nguyen University of Technology, Thai Nguyen, Vietnam

Vi Thi Phuong Thao, Faculty of International Training, Thai Nguyen University of Technology, Thai Nguyen, Vietnam

Doan Thanh Binh, Faculty of Automotive and Power Machinery Engineering, Thai Nguyen University of Technology, Thai Nguyen, Vietnam Nguyen Thanh Cong, Faculty of Automotive and Power Machinery Engineering, Thai Nguyen University of Technology, Thai Nguyen, Vietnam compare the performance of the air suspension systems for reducing the negative impacts on the road surface when vehicle moves on the different road conditions [6]. The fuzzy logic controller (FLC) was applied to control variable values of hydraulic shock absorber to improve vehicle ride comfort and road surface friendliness [7], [8]. The damping coefficient of hydraulic shock absorber of an air suspension system was controlled by using the fuzzy logic controller (FLC) in the direction of vehicle ride comfort and road surface friendliness [9]. The vertical dynamic tire loads of a semi-trailer truck acting on road surface equipped with air and leaf- spring suspension systems were analyzed based on a dynamic load coefficient (DLC) and a half- vehicle dynamic model [12]. Two different air spring models (classic air spring; dynamic air spring model) were proposed and analyzed for their characteristic influence on vehicle ride comfort and road surface friendliness.

In this study, a dynamic model combining hydraulic shock absorber and air spring of an air suspension system is set up to determine vertical forces and then these vertical forces are connected to a quarter-vehicle dynamic model of a heavy truck to analyze the effect of the damping coefficients of hydraulic shock absorber on road surface friendliness based on a dynamic load coefficient (DLC).

\section{QUARTER-VEHICLE DYNAMIC MODEL}

\section{A. Dynamic model of an air suspension system}

A dynamic model of both a hydraulic shock absorber and an air spring of an air suspension system is established to determine vertical forces, as shown in Fig.2.

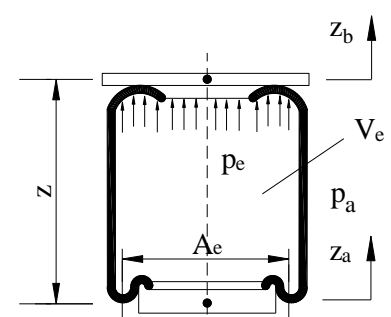

(a)Schematic of an air spring

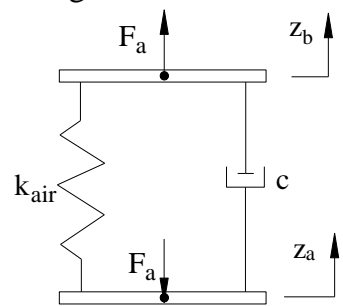

(b) Dynamic model
Figure 1: Dynamic model of an air suspension system

Explanation of Fig.1, $\mathrm{p}_{\mathrm{e}}$ is the absolute pressure in the air chamber, $p_{a}$ is the atmospheric pressure, and $A_{e}$ is the effective area, $V_{e}$ and $A_{e}$ are the effective volume and area; $z_{a}$ and $z_{b}$ are the displacements of axle and vehicle body, $k_{a}$ is stiffness coefficient of air and leaf spring suspensions, $c$ is damping coefficient of a hydraulic shock absorber.

The schematic of an air spring is shown in Fig.1(a). The 
absolute pressure of the air spring and the air spring elastic force $F_{a}$ in the axial direction provided by the compressed air in the bellow are given as below

$$
F_{a}=\left(p_{e}-p_{a}\right) A_{e}=k_{a}\left(z_{b}-z_{a}\right)=k_{a} z \text {. }
$$

According to Hooke's law [10], the stiffness $k_{a}$ of an air spring can be calculated by Eq.(2)

$$
k_{a}=\frac{d F_{a}}{d z}=\frac{d p_{e}}{d z} A_{e}+\left(p_{e}-p_{a}\right) \frac{d A_{e}}{d z} .
$$

where, $\mathrm{z}$ is the vertical displacement of air spring; $\mathrm{z}=\mathrm{Z}_{\mathrm{b}}-\mathrm{Z}_{\mathrm{a}}$ is the difference between vehicle body mass and vehicle axle mass.

$$
p_{e} V_{e}^{n}=\text { const. }
$$

where, $\mathrm{n}$ is the polytropic exponent and depends on the following working conditions: $\mathrm{n}=1$ for the isothermal condition, $\mathrm{n}=1.4$ for the adiabatic condition, and $1<\mathrm{n}<1.4$ for the polytropic condition.

Differentiating Eq.(3) with respect to $\mathrm{z}$ yields:

(4)

$$
\frac{d}{d z}\left(p_{e} V_{e}^{n}\right)=V_{e}^{n} \frac{d p_{e}}{d z}+n p_{e} V_{e}^{n-1} \frac{d V_{e}}{d z}=0 .
$$

$$
\text { And } \frac{d V_{e}}{d z}=-A_{e} \text {. }
$$

From the equations above, the equivalent stiffness can be given as follows:

$$
\begin{aligned}
& k_{a}=n\left(p_{g}+p_{a}\right) \frac{A_{e}^{2}}{V_{e}}+p_{g} \frac{d A_{e}}{d z} \\
& =n\left[p_{a}+\left(p_{0}+p_{a}\right)\left(\frac{V_{0}}{V_{e}}\right)^{n}-p_{a}\right] \frac{A_{e}^{2}}{V_{e}} \\
& +\frac{d A_{e}}{d z}\left[\left(p_{0}+p_{a}\right)\left(\frac{V_{0}}{V_{e}}\right)^{n}-p_{a}\right] .
\end{aligned}
$$

From the equations above, the equivalent stiffness can be given as follows:

$$
\begin{aligned}
& k_{a}=n\left[p_{a}+\left(p_{0}+p_{a}\right)\left(\frac{V_{0}}{V_{e}}\right)^{n}-p_{a}\right] \frac{A_{e}^{2}}{V_{e}} \\
& +\left.\left[\left(p_{0}+p_{a}\right)\left(\frac{V_{0}}{V_{e}}\right)^{n}-p_{a}\right] \frac{d A_{e}}{d z}\right|_{z=0} .
\end{aligned}
$$

where, $\mathrm{V}_{0}$ is the initial effective volume; $\mathrm{p}_{0}$ is the initial pressure in air bag.

The effective volume and area are defined as

$$
\left\{\begin{array}{l}
V_{e}=V_{0}-\alpha\left(z_{b}-z_{a}\right) \\
A_{e}=A_{0}+\beta\left(z_{b}-z_{a}\right)
\end{array}\right. \text {. }
$$

where, $\mathrm{A}_{0}$ is the initial effective volume; $\alpha$ and $\beta$ are the change of the effective volume and area with respect to $\mathrm{z}$

The dynamic model of air suspension system is shown in Fig 1.(b), the vertical force of the air suspension is defined as

$$
F_{a}=k_{a}\left(z_{b}-z_{a}\right)+c\left(\dot{z}_{b}-\dot{z}_{a}\right) \text {. }
$$

\section{B. Quarter-vehicle dynamic model of a heavy truck}

A quarter-vehicle dynamic model of a heavy truck with two degrees of freedom is established to analyze the effect of the damping coefficients of hydraulic shock absorber on road surface friendliness based on a dynamic load coefficient (DLC), as shown in Fig.2. Explanation of Fig.2, $\mathrm{m}_{\mathrm{b}}$ is the vehicle body mass, $\mathrm{m}_{\mathrm{a}}$ is vehicle axle mass, $\mathrm{z}_{\mathrm{b}}$ and $\mathrm{z}_{\mathrm{a}}$ are the vertical displacements of vehicle body, and vehicle axle masses, $\mathrm{k}_{\mathrm{a}}, \mathrm{c}$, and $\mathrm{k}_{\mathrm{t}}, \mathrm{c}_{\mathrm{t}}$ are the stiffness and damping coefficients of the vehicle and tire, $\mathrm{q}$ is road roughness random excitation.

The equations of vehicle motion: A combined method of the multi-body system theory and D'Alembert's principle is chosen [3]. The multi-body system theory is used to separate the system into subsystems which are linked by the force and moment equations. D'Alembert's principle is used to create force and moment equations in order to describe vehicle dynamic subsystems. The equations of motion can be written as

$$
\left\{\begin{array}{l}
m_{b} \ddot{z}_{b}=m_{b} g-F_{a} \\
m_{a} \ddot{z}_{a}=m_{a} g+F_{a}-\left[k_{t}\left(z_{a}-q\right)+c_{t}\left(\dot{z}_{a}-\dot{q}\right)\right]^{\prime}
\end{array} \mathrm{z}_{\mathrm{b}}\right.
$$

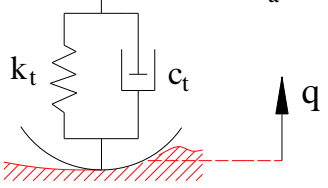

Figure 2: quarter-vehicle dynamic model of a heavy truck with two degrees of freedom

\section{Road surface roughness excitation $(q)$}

The road surface roughness plays an important role in analyzing dynamic analysis of the vehicle which is assumed to be a zero-mean stationary Gaussian random process. It can be generated through the inverse Fourier transformation [12].

$$
q(t)=\sum_{i=0}^{N} \sqrt{2 \Delta n G_{d}\left(n_{i}\right)} \cos \left(2 \pi n_{i} t+\varphi_{i}\right) .
$$

where, $\Delta \mathrm{n}$ is within a frequency band; $\varphi_{\mathrm{i}}$ is the random phase uniformly distributed from 0 to $2 \pi ; G_{q}\left(i \Delta \mathrm{n}_{0}\right)$ is the road roughness coefficient which is defined for typical road classes from A to F according to ISO 8068(1995)[13].

\section{DYNAMIC LOAD COEFFICIENT}

In order to evaluate the dynamic wheel load acting on the road surface, the indicators such as dynamic load-sharing coefficient (DLSC) and dynamic load coefficient (DLC), the dynamic load stress factors, and the maximal and the minimal vertical dynamic load factor [14] were selected for analysis by researchers. In this study, dynamic load coefficient (DLC) is selected for analysis. The dynamic load coefficient DLC is defined as the ratio of a ratio of the root mean square (RMS) of the vertical dynamic tire force over static load.

$$
D L C=\frac{F_{t, R M S}}{F_{s}} .
$$

where $F_{t, R M S}$ and $F_{S}$ are the root mean square of the vertical dynamic and the static tire force. The value of the DLC is in range of 0.05 to 0.3 under normal operating conditions. It may reach zero when the wheels move on a special smooth road or increase up to 0.4 when the tires of the axles spend a significant proportion of their time disconnecting the road surface[15]. 


\section{ANALYSIS AND DISCUSSION}

In order to analyze the effect of the damping coefficients of hydraulic shock absorber on road surface friendliness, the dynamic differential equation of vehicle Eq.(10) is simulated and analyzed by Matlab/Simulink software with a set of parameters of vehicle in Tab.1. The vertical dynamic tire loads acting on road surface with ISO class A road surface at $\mathrm{v}=20 \mathrm{~m} / \mathrm{s}$ and full load (Case 1) is shown Fig.3. The vertical dynamic tire loads acting on road surface with ISO class B road surface at $\mathrm{v}=20 \mathrm{~m} / \mathrm{s}$ and full load (Case 2) is shown Fig.4. The vertical dynamic tire loads acting on road surface with ISO class $C$ road surface at $\mathrm{v}=20 \mathrm{~m} / \mathrm{s}$ and full load (Case 2) is shown Fig.5.

Tabl 1: Parameters of the vehicle[2]

\begin{tabular}{|l|c|}
\hline \multicolumn{1}{|c|}{ Parameters } & Values \\
\hline $\mathrm{m}_{\mathrm{a}} / \mathrm{kg}$ & 1554 \\
\hline $\mathrm{m}_{\mathrm{b}} / \mathrm{kg}$ & 4871 \\
\hline $\mathrm{c} /(\mathrm{N} . \mathrm{s} / \mathrm{m})$ & $2.5539 \times 10^{4}$ \\
\hline $\mathrm{k}_{\mathrm{t}} /(\mathrm{N} / \mathrm{m})$ & $1.7933 \times 10^{6}$ \\
\hline $\left.\mathrm{c}_{\mathrm{t}} / \mathrm{N} . \mathrm{s} / \mathrm{m}\right)$ & $2.414 \times 10^{3}$ \\
\hline $\mathrm{p}_{\mathrm{a}} / \mathrm{Pa}$ & $0.1 \times 10^{6}$ \\
\hline $\mathrm{V}_{0} / \mathrm{m}^{3}$ & 0.0333 \\
\hline $\mathrm{A}_{0} / \mathrm{m}^{2}$ & 0.0906 \\
\hline $\mathrm{p}_{0} / \mathrm{Pa}$ & $2.865 \times 10^{6}$ \\
\hline $\mathrm{n}$ & 1.4 \\
\hline
\end{tabular}

From the results in the Fig.3, Fig.4 and Fig.5, we can determine the DLC values through Eq.(12) and DLC values are $0.0776,0.1644$, and 0.2967 , respectively. The results indicate that DLC values increase with variable road conditions, which leads to adverse effects on the road surface. The effect of the damping coefficients of hydraulic shock absorber on road surface friendliness will continue to investigate below.

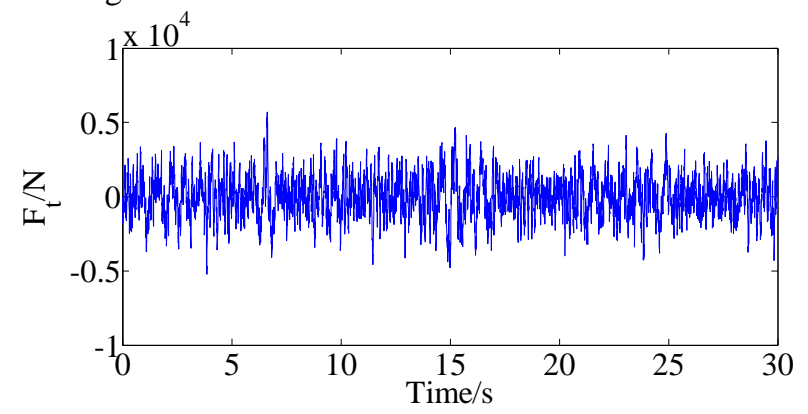

Figure 3: The vertical dynamic tire loads acting on road surface

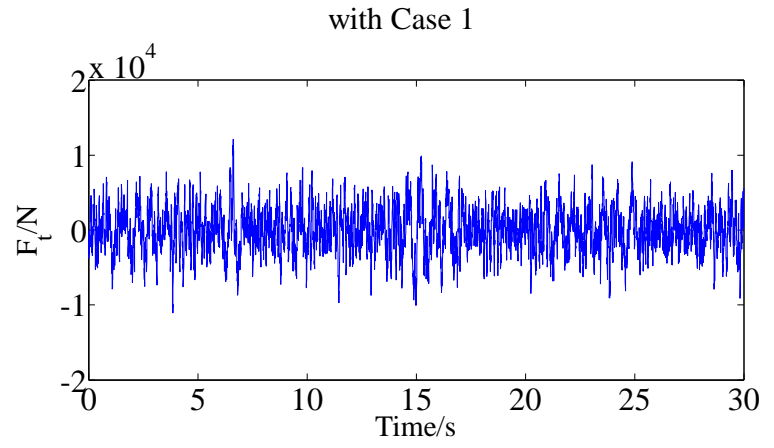

Figure 4: The vertical dynamic tire loads acting on road surface with Case 2

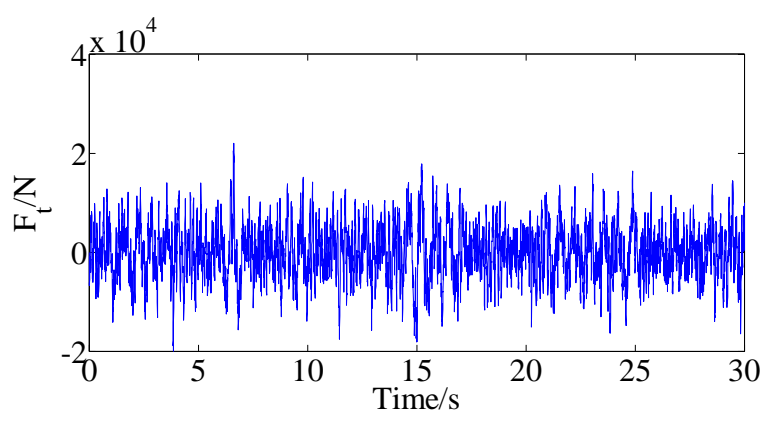

Figure 5: The vertical dynamic tire loads acting on road surface with Case 3

The damping coefficient values of hydraulic shock absorber $c_{j}=\left[\begin{array}{lllll}0.5 & 1 & 1.5 & 2 & 2.5\end{array}\right] \mathrm{c}$ in which $\mathrm{c}$, the value of the original damping coefficient of hydraulic shock absorber, is selected to investigate its effects on DLC value when vehicle operates under three conditions such as Case 1, Case 2, Case 3. The DLC values with variable damping coefficient value under three conditions are shown in Fig.6.

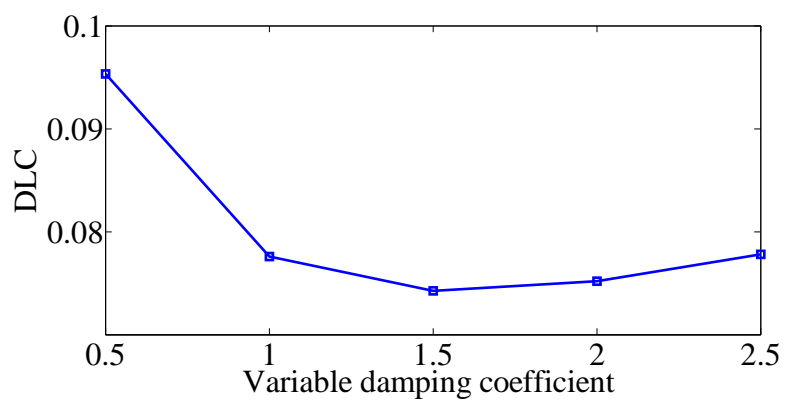

(a) Case 1

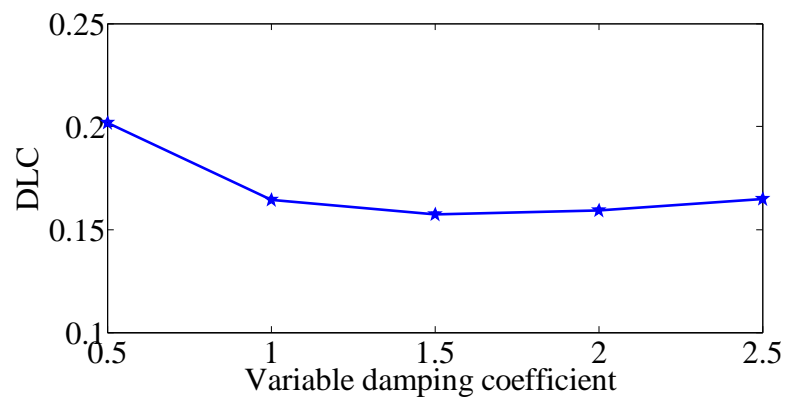

(b) Case 2

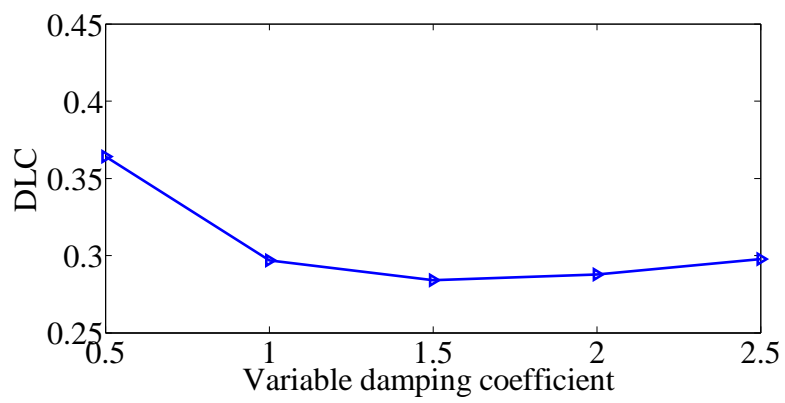

(c) Case 3

Figure 6: DLC values with variable damping coefficient values

The results in Fig. 6 show that $c_{j}$ value reduces in comparison with original value $\mathrm{c}$, and DLC value increases leading to adverse effects on the road surface. The $c_{j}$ value increases in comparison with original value $\mathrm{c}$, initial DLC value reduces and then increases with three cases. Especially, DLC value of $1.5 \mathrm{xc}$ reaches the minimum value with all three cases, which makes road surface friendliness improve significantly. 


\section{Effect of Design Parameter of Hydraulic Shock Absorber of Heavy Truck Air Suspension System on Road Surface Friendliness}

\section{CONCLUSION}

This paper proposes a dynamic model of both hydraulic shock absorber and air spring of an air suspension system to analyze the vertical force of a heavy truck air suspension system. The model is then connected with a quarter-vehicle dynamic model of a heavy truck to evaluate the effect of damping coefficient of hydraulic shock absorber on road surface friendliness. The obtained results indicate that the DLC value increases with the reduction of damping coefficient, and the initial DLC value reduces and then increases with the reduction of damping with the increase of damping coefficient with three cases. Especially, the DLC value of $1.5 \mathrm{c}$ respectively reduce by $8.8 \%$ in comparison with $1.0 \mathrm{c}$ value and increase by $5.1 \%$ with $1.0 \mathrm{c}$ value with Case 2 .

\section{ACKNOWLEDGMENT}

This research was financially supported by Thai Nguyen University of Technology, TNUT, Viet Nam.

\section{REFERENCES}

[1] Woodrooffe, John. "Heavy Truck Suspension Damper Performance for Improved Road Friendliness and Ride Quality." SAE Transactions, vol. 104, 1995, pp. 575-580.

[2] Le Van Quynh, Vi Thi Phuong Thao. "Effect of Operating Conditions on Vehicle Ride Comfort and Road Surface Friendliness with Air Suspension System", International Research Journal of Engineering and Technology (IRJET), Vol.7(6), 2020, p.7671-7675.

[3] L. V. Quynh, N. V. Tuan, V. T. P. Thao, and L. Q. Duy, "Optimal design parameters of air suspension systems for semi-trailer truck. Part 1: modeling and algorithm," Vibroengineering PROCEDIA, vol. 33 , pp. 72-77, Oct. 2020.

[4] L. V. Quynh, N. V. Tuan, V. T. P. Thao, and L. Q. Duy, "Optimal design parameters of air suspension systems for semi-trailer truck. Part 2: results and discussion," Vibroengineering PROCEDIA, vol. 33, pp. 147-152, Oct. 2020.

[5] Sun, L. "Optimum design of "road-friendly" vehicle suspension systems subjected to rough pavement surfaces," Applied Dynamic Modelling, 26(5), 2002, pp. 635-652.

[6] V. Q. Le, "Comparing the performance of suspension system of semi-trailer truck with two air suspension systems," Vibroengineering PROCEDIA, vol. 14, pp. 220-226, Oct. 2017.

[7] Liem Nguyen Van, Jianrun Zhang, Quynh Le Van, Renqiang Jiao. "Study of fuzzy control for cab's isolation system of heavy truck." Vibroengineering PROCEDIA, Vol. 10, 2016, pp. 309-314.

[8] V. Q. Le and V. L. Nguyen, "Ride comfort performance of heavy truck with three control cases of semi-active isolation systems," Vibroengineering PROCEDIA, vol. 22, pp. 93-98, Mar. 2019.

[9] Zhou Huaxiang, Wu Xiaoyan, Wang Peiling "Control of the air suspension system of semi-trailer trucks to enhance the road friendliness." Vibroengineering PROCEDIA, Vol. 35, 2020, pp. 13-19.

[10] Xiao, P., Gao, H., Shi, P., \& Niu, L. "Research on air suspension with novel dampers based on glowworm swarm optimization proportional-integral-derivative algorithm." Advances in Mechanical Engineering, 10(8), 2018m 168781401879171.

[11] Vu Thi Hien, Le Xuan Long, Le Van Quynh, Nguyen Van Liem and Bui Van Cuong. "Effect Analysis of the Parameters of Hydro-Pneumatic Suspension System on Vehicle Ride Comfort". International Journal of Advanced Research in Engineering and Technology (IJARET), 12(1), 2021, pp. 422-430.

[12] Le Van Quynh, Bui Van Cuong, Nguyen Van Liem, Le Xuan Long and $\mathrm{Vu}$ The Truyen." Analysis of dynamic wheel loads of a semi-trailer truck with air-spring and leaf- spring suspension systems," ARPN Journal of Engineering and Applied Sciences, Vol.15(2), 2020, pp.145-152.

[13] ISO 8608. Mechanical Vibration-Road Surface Profiles-Reporting of Measured Data. International Organization for Standardization, 1995.

[14] Le V.Q., Zhang J., Liu X., Wang Y. "Nonlinear dynamic analysis of interaction between vehicle and road surfaces for 5-axle heavy truck". Journal of Southeast University (English Edition), Vol. 27(4), 2011, pp. 405-409.

[15] Rosnawati Buhari, Munzilah Md Rohani, et al. "Dynamic load coefficient of tyre forces from truck axles", Applied Mechanics and Materials, Vol. 405( 408), 2013, pp.1900-1911.

[16] Moheyeldein, M. M., Abd-El-Tawwab, A. M., Abd El-gwwad, K. A., \& Salem, M. M. M. "An analytical study of the performance indices of air spring suspensions over the passive suspension". Beni-Suef University Journal of Basic and Applied Sciences. Vol.7(4), 2018, pp. 525-534
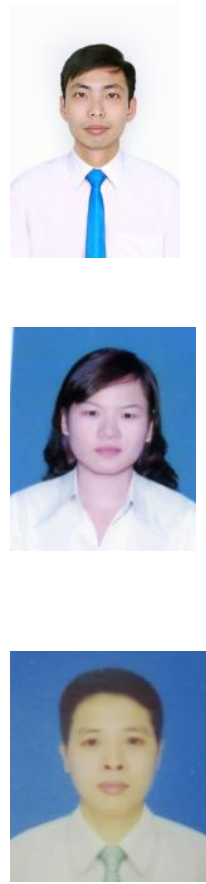

Bui Van Cuong received the MSc. degree in Vehicle Engineering from Thai Nguyen University of Technology, Thai Nguyen, Vietnam. He is currently a lecturer at the Department of Automotive Engineering, Faculty of Automotive and Power Machinery Engineering, Thai Nguyen University of Technology, Vietnam. His current research interests include Vehicle dynamics, Vehicle vibration and noise.

Vi Thi Phuong Thao received the MSc. in Linguistics from Hanoi University, Ha Noi, Vietnam. She is currently a lecturer at the Division of Language Education, Faculty of International Training, Thai Nguyen University of Technology, Vietnam. Her current research interests include Communicative-oriented Language Teaching Methodologies, Applied Linguistics.

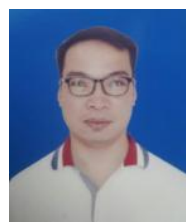

Doan Thanh Binh received the MSc. degree in Vehicle Engineering from Thai Nguyen University of Technology, Thai Nguyen, Vietnam. He is currently a lecturer at the Department of Automotive Engineering, Faculty of Automotive and Power Machinery Engineering, Thai Nguyen University of Technology, Vietnam. His current research interests include Vehicle Dynamics, Vehicle Vibration and Noise.

Nguyen Thanh Cong received the MSc. degree in Mechanical Engineering from Thai Nguyen University of Technology, Thai Nguyen, Vietnam. He is currently a lecturer at Power Machinery Engineering, Faculty of Automotive and Power Machinery Engineering, Thai Nguyen University of Technology, Vietnam. His current research interests include Vibration and Noise, Heat and Heat Transfer in Engineering. 